\title{
Genetic Engineering of Sugarcane for Drought and Salt Tolerant Transgenic Plants Expressing the BcZAT12 Gene
}

\author{
S. Saravanan ${ }^{1}$, K.K. Kumar ${ }^{1}$, M. Raveendran $^{1}$, D. Sudhakar ${ }^{1}$, L. Arul ${ }^{2}$, E. Kokiladevi ${ }^{2}$, \\ T. Raguchander ${ }^{3}$, S. mani $^{4}$ and P. Balasubramanian ${ }^{1}$ \\ ${ }^{1}$ Department of Plant Biotechnology, ${ }^{2}$ Department of Plant Molecular Biology and \\ Bioinformatics, ${ }^{3}$ Department of Plant Pathology, Centre for Plant Protection Studies, \\ ${ }^{4}$ Department of Soil Science and Agricultural Chemistry, Directorate of Natural Resources \\ and Management, Tamil Nadu Agricultural University, Coimbatore 641003, Tamilnadu, India
}

*Corresponding author

\section{Keywords \\ Sugarcane, \\ BcZAT12 gene, \\ Zinc finger protein, \\ Transcription \\ factor, \\ Agrobacterium \\ mediated genetic \\ transformation, \\ Drought-salt \\ tolerant}

\section{Article Info}

Accepted:

10 June 2018

Available Online:

10 July 2018

\section{A B S T R A C T}

Sugarcane (Saccharum officinarum L.) is one of the staple sources of sweetening in the world and is of substantial importance to the economy of several sugarcane producing countries. Sugarcane is a major cash crop cultivated in many parts of the world, especially in the tropics. Commercial sugarcane (Poaceae), mainly the complex aneuploidy, polyploidyinterspecific hybrids of Saccharum officinarum and S. spontaneum is a major field crop accounting for about 85 per cent of sugar production worldwide. Sugarcane crop frequently encounters abiotic stresses that adversely affect growth, development and productivity. Among the environmental stresses, Drought and Salinity affect the cane productivity and yield. Genetic engineering approach is a viable method to engineer Drought and Salt stress tolerance in crop plants. BcZAT12 gene isolated from Brassica carinata is used for sugarcane transformation in the present study. To confer abiotic stress tolerance, candidate gene pCAMBIA1300-BcZAT12was used to transform by agrobacterium mediated, the sugarcane cultivar, Co86032. Forty five independent transgenic lines of sugarcane transformed with BcZAT12 gene were generated. PCR analysis confirmed the integration of Drought and Salt stress tolerant gene BcZAT12and hygromycin (hpt) in all the 45 putative transgenic sugarcane plants found to be positive. By screening these 45 lines for the drought and salt tolerance, we identified 10 lines, which are highly tolerant to drought and salt. Out of 10 lines, 3 lines were randomly selected for morphological, physiological, biochemical and molecular analyses. These analyses revealed that growth and vigor, relative water content, photosynthetic rate, transpiration rate, stomatal conductance, chlorophyll content, proline and glycine betaine content were higher in the stress tolerant transgenic plants compared to control plants. Moreover, RTPCR analysis revealed that highly tolerant lines exhibited a higher level of "BcZAT12" expression compared to less tolerant lines. In conclusion, this study has established that "BcZAT12" gene can confer drought and salt tolerance in sugarcane, indicating that this gene can be exploited in the improvement of other crops. 


\section{Introduction}

Sugarcane is a tall perennial grass of the genus Saccharum, native to warm temperate to tropical regions of Asia. Different species likely originated in different locations with $S$. barberi originating in India and $S$. edule and S. officinarum coming from New Guinea. They have stout, jointed, fibrous stalks that are rich in sugar and measure two to six meters tall. The thick stalk stores energy as sucrose in the sap. All sugarcane species inbreed and the major commercial cultivars are complex hybrids. Sugarcane have a large genome size $(2 \mathrm{C}=7440 \mathrm{Mbp})$ and varying among cultivars due to its polyploidy genome. Sugarcane cultivars have varying ploidy levels that range from $5 \mathrm{X}$ to $14 \mathrm{X}(\mathrm{X}=5,6,8,10,12,14)$ and chromosomal mosaicism (Burner and Legendre, 1994). Most cultivated sugarcanes were clones of the high sucrose producing cultivar Saccharum officinarum which contain 2n=70-122chromosomes. Physiological and genetic investigations indicate that most abiotic stress tolerance traits are complex controlled by more than one gene and highly influenced by environmental variation (Blum, 1988).The quantification of tolerance often difficult and direct selection under field conditions is generally difficult because uncontrollable environmental factors affect the precision and repeatability of such trials. Stress tolerance is a developmentally regulated, stage-specific phenomenon; tolerance at one stage of plant development may not be correlated with tolerance at other developmental stages.

Combination of recombinant-DNA technology, gene-transfer method, and tissueculture techniques has led to efficient transformation and production of transgenics in a wide variety of crop plants (James, 2007). This technique involves use of structural genes (key enzymes for biosynthesizing osmolytes, redox proteins and detoxifying enzymes and stress-induced LEA proteins) and regulatory genes (Dehydration-Responsive ElementBinding Factors (DREB), Zinc Finger proteins and NAM, ATAF and CUC Transcription factor (NAC) genes).

\section{Materials and Methods}

Genetic transformation of sugarcane with BcZAT12 gene

\section{Gene construct}

The BcZAT12 gene cassette cloned in the backbone of the binary vector, pCAMBIA1300 was designated as pCAMBIA1300-BcZAT12 (Figure 1). The binary vectors, pCAMBIA1300BcZAT12carrying a BcZAT12gene driven by pLEA promoter and Nosterminator, the vector pCAMBIA1300harbours the hygromycin phosphotransferase (hpt) gene driven by CaMV35S promoter and Nosterminator, which confers resistance to hygromycin as plant selectable marker.

\section{Back transformation}

Agrobacterium tumefaciens strains, LBA4404 (pCAMBIA1300-BcZAT12) were used for transformation of sugarcane cultivar of Co86032 genotypes used for agrobacterium mediated transformation. In order to confirm the presence of the constructs, pCAMBIA1300-BcZAT12in LBA4404, the total genomic DNA was isolated from respective Agrobacterium strains and the DNA was used to transform Escherichia coli DH5- cells. Total genomic DNA was isolated from the Agrobacterium strains by following modified protocol of Chen and Kuo (1993).

\section{Preparation of competent cells}

Single colony of E. coli strain DH5 $\square$ was inoculated in $3 \mathrm{ml}$ of $\mathrm{LB}$ broth $(10 \mathrm{~g} / \mathrm{l}$ 
tryptone, $10 \mathrm{~g} / \mathrm{l} \mathrm{NaCl}, 5 \mathrm{~g} / 1$ yeast extract, agar $20 \mathrm{~g} / \mathrm{l}, \mathrm{pH}$ 7.2) and grown at $37^{\circ} \mathrm{C}$. An aliquot of $1.0 \mathrm{ml}$ overnight grown culture was inoculated into $50 \mathrm{ml}$ of LB broth and grown till 0.5-0.6O.D.at $600 \mathrm{~nm}$. After incubation in ice for $20 \mathrm{~min}$, the cells were centrifuged at $4000 \mathrm{rpm}$ for $10 \mathrm{~min}$ at $4^{\circ} \mathrm{C}$. The bacterial pellet was resuspended in $10 \mathrm{ml}$ of sterile icecold $\mathrm{CaCl}_{2}(50 \mathrm{mM})$ and incubated on ice for $20 \mathrm{~min}$. The cells were centrifuged and resuspended in $2.0 \mathrm{ml}$ of sterile ice-cold 100 $\mathrm{mM} \mathrm{CaCl} \mathrm{Cl}_{2}$ containing 15 per cent glycerol. Cell suspension thus obtained was aliquoted into $100 \square 1$ volumes, frozen in liquid N2 and stored at $-70{ }^{\circ} \mathrm{C}$.

\section{Bacterial transformation}

An aliquot of 50-100ng of purified total DNA isolated from LBA4404 (pCAMBIA1300BcZAT12) was mixed with $100 \mu \mathrm{l}$ of competent cells. The mixture was then incubated on ice for $30 \mathrm{~min}$, followed by a heat shock treatment at $42{ }^{\circ} \mathrm{C}$ for $90 \mathrm{sec}$ and immediately placed on ice for $10 \mathrm{~min}$. Then the bacterial suspension was grown in $1.0 \mathrm{ml}$ of LB broth for $1 \mathrm{~h}$ at $37^{\circ} \mathrm{C}$ in a rotary shaker set at $200 \mathrm{rpm}$. After incubation, $100 \mu \mathrm{l}$ of cell suspension was plated on to an LB agar medium containing $50 \mathrm{mg} / \mathrm{l}$ kanamycin and grown overnight at $37^{\circ} \mathrm{C}$.

\section{Agrobacterium-mediated transformation of Sugarcane cultivar of $\mathbf{C o 8 6 0 3 2}$}

\section{Plant material}

Shoot tops of Co86032 were collected from 5 to 6 months old sugarcane planted in the research field of Sugarcane Breeding Institute, Indian Council of Agricultural Research, Coimbatore, Tamil Nadu. Explants were taken from apparently healthy and vigorous growing cane. Culms were removed from the plants and cut $20-30 \mathrm{~cm}$ below the uppermost visible development giving a $10 \quad-15 \quad \mathrm{~cm}$ spindle of leaves attached to the shoot apex. Three to four outer mature leaves were removed from the field collected explants and under sterile hood, additional outer leaves were removed to obtain an immature leaf rolls of about $1 \mathrm{~cm}$ diameter thickness that comprise the innermost 5-6 tightly furled spindle leaves. Since the young developing leaves are very tightly furled, the innermost leaves will be free from microbial contamination. A $10-15 \mathrm{~cm}$ long basal portion of the leaf roll, starting from the leaf base, innermost whorls of immature leaves were cut into small segments or pieces $(1-1.5 \mathrm{~cm}$ X 0.5 $\mathrm{cm})$ to serve as explants.

\section{Preparation of Agrobacterium culture}

Agrobacterium strains, $\quad$ LBA4404 (pCAMBIA1300-BcZAT12) was streaked onto YEP medium (10 g/l peptone, $5 \mathrm{~g} / \mathrm{l} \mathrm{NaCl}$, $10 \mathrm{~g} / \mathrm{l}$ yeast extract and agar $20 \mathrm{~g} / \mathrm{l}, \mathrm{pH} 7.0$ ) containing $50 \mathrm{mg} / \mathrm{l}$ hygromycin (hpt) and 10 $\mathrm{mg} / \mathrm{l}$ rifampicin and grown at $28{ }^{\circ} \mathrm{C}$ overnight. From the plate, a single colony was inoculated into $3.0 \mathrm{ml}$ of YEP medium containing appropriate antibiotics and the culture was incubated at $28^{\circ} \mathrm{C}$ on a rotary shaker at 200 rpm. From the overnight-grown culture, 0.5 $\mathrm{ml}$ was transferred into $30 \mathrm{ml}$ of YEP liquid medium containing appropriate antibiotics. The culture was grown overnight and the bacterial cells harvested by centrifugation at 4,000 rpm for $10 \mathrm{~min}$. The pellet was resuspended in $30 \mathrm{ml}$ of AAM broth (Toriyama and Hinata, 1985) and used for cocultivation.

\section{Co-cultivation}

The embryogenic calli were obtained after three round of sub culturing in callus induction medium containing MS basal salts, MS vitamins, $3 \mathrm{mg} / \mathrm{l}$ of 2,4-D, $30 \mathrm{~g} / \mathrm{l}$ sucrose, $4 \mathrm{~g} / \mathrm{l}$ phytagel. Embryogenic calli were carefully submerged in the Agrobacterium 
suspension $(30 \mathrm{ml})$ in a sterile glass vessel for 20 min with gentle swirling. After 20 mins, they were blotted dry on sterile filter paper and transferred to the co-culture medium. After $48 \mathrm{~h}$ of co-cultivation in the dark at 26 ${ }^{\circ} \mathrm{C}$, the embryogenic calli were washed thrice with sterile distilled water and once with an aqueous solution containing $500 \mathrm{mg} / \mathrm{l}$ cefotaxime followed by three washes with sterile distilled water. After final washing, they were blotted dry on sterile paper and cultured on the MS basal salts, MS vitamin, $3.0 \mathrm{mg} / \mathrm{l}$ 2,4-D, $30 \mathrm{~g} / 1$ sucrose, $4 \mathrm{~g} / 1$ phytagel $50 \mathrm{mg} / \mathrm{l}$ hygromycin (hpt) and incubated at $25 \pm 2^{\circ} \mathrm{C}$ for in dark.

\section{Regeneration of putative transgenic plants}

After two days in proliferation medium, embryogenic calli were transferred to selection medium containing MS basal salts, MS vitamin, $3.0 \mathrm{mg} / \mathrm{l}$ 2,4-D, $30 \mathrm{~g} / 1$ sucrose, 4 $\mathrm{g} / \mathrm{l}$ phytagel $50 \mathrm{mg} / \mathrm{l}$ hygromycin and incubated at $25 \pm 2^{\circ} \mathrm{C}$ for $15-18$ days in dark. After 15 days, the actively growing embryogenic calli on selection medium were sub cultured onto a fresh selection medium and incubated at $25 \pm 2^{\circ} \mathrm{C}$ for 15 days followed by another round of subculture.

Embryogenic calli that survive third round of selection on hygromycin were transferred to a regeneration medium containing $\mathrm{MS}$ basal salts, MS vitamins, $30 \mathrm{~g} / \mathrm{l}$ of sucrose, $4 \mathrm{~g} / \mathrm{l}$ phytagel and with $1 \mathrm{mg} / \mathrm{l}$ of BAP, $1 \mathrm{mg} / \mathrm{l}$ of kinetin and $50 \mathrm{mg} / \mathrm{l}$ hygromycin. The calli were incubated under $16 \mathrm{hrs}$ photoperiod at $25 \pm 2{ }^{\circ} \mathrm{C}$ for 3-4 weeks for regeneration of shoots. The emerging shoots were transferred to the fresh regeneration medium. Shoots of 4$5 \mathrm{~cm}$ height with 2-3 leaves cultured on rooting medium containing full strength MS basal salts, MS vitamin, $1.0 \mathrm{mg} / \mathrm{l}$ of NAA, 30 $\mathrm{g} / \mathrm{l}$ of sucrose, $4 \mathrm{~g} / \mathrm{l}$ phytagel and $50 \mathrm{mg} / \mathrm{l}$ hygromycin.
Molecular analysis of putative transgenic plants

Total DNA was extracted from a small leaf bit excised from the putative transgenic sugarcane plants. The leaf bit was homogenized in 300 $\mu \mathrm{l}$ of extraction buffer (100 mM Tris- $\mathrm{HCl}, \mathrm{pH}$ 8.0, $1.4 \mathrm{M} \mathrm{NaCl}, 20 \mathrm{mM}$ EDTA and 0.2 per cent of 2-mercaptoethanol). The supernatant is extract with chloroform-isoamyl alcohol (24:1) and centrifuged at $12000 \mathrm{rpm}$ for 10 mins. To the supernatant, equal volume of icecold isopropanol was added and kept at $-20^{\circ} \mathrm{C}$ for $10 \mathrm{~min}$. The supernatant was discarded after centrifugation and the pellet dried for 15 min, dissolved in $30 \mu \mathrm{l}$ of $0.1 \mathrm{X}$ TE buffer. PCR analysis was performed to confirm the presence of abiotic stress tolerant gene BcZAT12, plant selectable marker gene hpt. PCR analysis was carried out using $100 \mathrm{ng}$ of genomic DNA in a $20 \mu \mathrm{l}$ reaction mixture containing $2.0 \mu \mathrm{l}$ of $10 \mathrm{X}$ PCR buffer $(50 \mathrm{mM}$ Tris- $\mathrm{HCl} \mathrm{pH} 8.8,50 \mathrm{mM} \mathrm{KCl}$ and $1.5 \mathrm{mM}$ $\mathrm{MgCl} 2$ ), $200 \mu \mathrm{M}$ of each dNTPs, $0.5 \mu \mathrm{l}$ of each primer Forward and Reverse and 2 units of Taq DNA polymerase. The primer pair of forward primer and a reverse primer was used to amplify a $258 \mathrm{bp}$ internal sequence of BcZAT12 gene. The temperature used for amplification as following: pre-incubation at $94^{\circ} \mathrm{C}$ for 5 mins, leading to 35 cycles of denaturation at $94^{\circ} \mathrm{C}$ for $1 \mathrm{~min}$, annealing at $57^{\circ} \mathrm{C}$ for $1 \mathrm{~min}$ and synthesis at $72^{\circ} \mathrm{C}$ for 1 min, followed by extension at $72^{\circ} \mathrm{C}$ for 5 mins. Amplified PCR product $(20 \mu \mathrm{l})$ was subjected to electrophoresis on 1.2 per cent agarose gel and visualized under UV light.

Screening for abiotic stress tolerance in transgenic sugarcane transformed with BcZAT12

\section{Screening for drought tolerance}

Forty five independent lines with BcZAT12 gene of transgenic sugarcane were screened 
for their level of drought tolerance. Setts were collected from 7 to 8 month old mature cane and planted in the ridges and furrow formed in transgenic green house. First irrigation is given immediately after planting the sugarcane setts. Drought tolerance was assessed by not irrigating the plants for different time intervals viz., 15, 30, 45, 60 and 75 days. The plants were scored accordingly to the phenotypic appearance as highly tolerant, tolerant, moderately tolerant, and susceptible.

The planting material of transgenic sugarcane cultivar, Co86032 was taken from six month old healthy cane, free from pest, disease and cut into setts having two buds in each. Planting was carried out using completely randomized block design (CRD) replicated thrice. The concrete pot of size $18 \mathrm{~cm} \times 15 \mathrm{~cm}$ $\mathrm{x} 10 \mathrm{~cm}$ length, width and bottom, respectively were filled with sandy loam soil mixed with vermicomposting and used for planting the setts. The setts were planted in triangle and irrigation once in two days interval till drought stress is applied. Drought treatment was given by withholding irrigation after 60 days after transplanting. Then rewatering was done on the 75th day for the plants to recover from drought stress. Then drought stress applied till 90 days after transplanting. Then re-watering was done on the 90th day for the plants to recover second time from drought stress. Then drought stress was applied till 105 days after transplanting.

\section{Screening for salinity tolerance}

Forty five independent lines with BcZAT12 gene of transgenic sugarcane were screened for their level of salinity tolerance. The transgenic plants were grown under greenhouse condition, from three month old plants leaves were cut into $0.7 \mathrm{~cm}$ leaf disc or $1.2 \mathrm{~cm}$ leaf square. Then the cut leaves were suspended in $100 \mathrm{mM} \mathrm{NaCl}$ solution and incubated under 16 hours of light at $25^{\circ} \mathrm{C}$ days. Scoring of the symptoms was done at daily interval upto 7 days and the data recorded. All the 45 transgenic sugarcane lines were screened for their level of salinity tolerance in green house condition. Bud chips were collected from 7-8 months old transgenic sugarcane plants and planted in small plastic pots. Then $1 \% \mathrm{NaCl}$ solution was applied to germinating sugarcane bud chips and the degree of salinity tolerance was assessed during germination.

\section{Morphological parameters measured in drought stressed transgenic sugarcane}

Morphological parameters were recorded at 30 days after drought stress (90 DAT) in sugarcane cultivar transformed with drought tolerant gene. Plant growth attributes such as plant height, leaf length, leaf width, internode elongation, tiller growth from collar region and number of bud produced per plant, were measured with three replication were recorded and analyzed.

Physiological parameters analysis in the drought stressed transgenic sugarcane

\section{Leaf temperature}

Leaf temperature readings were collected using a hand-held infrared thermometer (Model OS530HR, Omega Engineering Inc., Stamford CT, USA) with leaf emissivity set at 0.95 . The measurement was made between 11.00 to 12.00 hours. During each LT measurement, the natural leaf orientation with respect to the sun was maintained to avoid shade effects

\section{Relative water content}

Leaf relative water content (RWC) was determined following the method of Matin et al., (1989). Twenty disks per plant were 
collected, immediately sealed in glass vials and quickly transported to the laboratory in an ice-cooled chest. Leaf disk fresh weights were determined within $2 \mathrm{~h}$ after excision. The turgid weight was obtained after rehydration in deionized water for $24 \mathrm{~h}$ at room temperature. After rehydration, leaves were quickly and carefully blotted dry with lint-free tissue paper before determining turgid weight. Dry weights were recorded after oven-drying leaf samples for $48 \mathrm{~h}$ at $80^{\circ} \mathrm{C}$.

\section{Chlorophyll content by SPAD-502 Meter}

A Minolta SPAD (Soil and Plant Analysis Division) Chlorophyll meter uses light source and detectors to determine the relative amount of chlorophyll in leaves by measuring the light transmitted by a plant leaf at two different wave lengths namely red $(650 \mathrm{~nm}$, where absorption is high) and near infrared (940 nm, where absorption is extremely low), the light transmitted by leaf is converted to electrical signals, and the ratio of intensities of transmitted light at the two wavelengths corresponding to SPAD readings is in SPAD units which are values defined by Minlota. SPAD readings were taken 30 days after the imposition of the stress by placing the SPAD meter at the middle of the third leaf from top. Total chlorophyll content was measured at twenty different places in selected plants and averaged to express in lux units.

\section{Portable photosynthetic system}

The third leaf (physiologically functional), fully expanded leaf at each collection date (30 days of water deficit) was used to evaluate as difference between transpiration rate, photosynthetic rate and stomatal conductance. All variables were analyzed in the Portable Photosynthesis System (LICor, model LI6400, "IRGA") with photosynthetically active radiation $1000 \mu \mathrm{mol} \mathrm{m}-2 \mathrm{~s}-1$.

\section{Chlorophyll fluorescence meter}

The chlorophyll fluorescence was measured using a portable plant efficiency analyzerPAM210 WALZ (Germany) fluorometer on attached leaves of each plant with three replication from the different transformation events and control plants. Measurements were made on dark-adapted leaves. Minimal fluorescence yield (Fo) was obtained upon excitation with a weak measuring beam from a pulse light-emitting diode. Maximal fluorescence yield (Fm) was determined after exposure to a saturating pulse of white light to close all reaction centers. The $\mathrm{Fv} / \mathrm{Fm}$ ratio representing the activity of PSII was used to assess the functional damage to the plants. A single leaf per plant constituted each replicate.

\section{Biochemical analysis done in drought stressed transgenic sugarcane}

\section{Proline estimation}

Five hundred $\mathrm{mg}$ of fresh leaf sample was weighed and transferred to a mortar. The sample was macerated with $10 \mathrm{~mL}$ of $3 \%$ sulphosalicylic acid and transferred to a centrifuge tube. The contents were centrifuged at 4,000 rpm for 10 minutes. After centrifugation, $2 \mathrm{~mL}$ of the supernatant was collected in a test tube. To this, $2 \mathrm{~mL}$ of acid ninhydrin and $2 \mathrm{~mL}$ of glacial acetic acid was added. The test tubes were kept in water bath for one hour and then cooled under tap water. The solution was transferred to a separating funnel and then $4 \mathrm{~mL}$ of toluene was added. The solution was uniformly shaken for 30 seconds until it formed two different layers. The colorless bottom layer was discarded and the upper pink colour solution was collected in a fresh test tube and the optical density was measured at $520 \mathrm{~nm}$. Toluene was used as blank. Standard curves were prepared with every set of plant samples. Standard were analyzed in duplicates, unknown samples, in triplicate. 


\section{Glycine betaine estimation}

Glycine betaine in nontransgenic and transgenic sugarcane lines was analysed based on Grattan and Grieve, 1983. The drought stressed transgenic and non transgenic sugarcane plants was freshly harvested, placed in paper bags and dried in an oven at $80^{\circ} \mathrm{C}$ for 4 days. After the tissue was dried, it was ground in pestle and mortar and stored at room temperature in glass vials. The dried finelyground plant material $(500 \mathrm{mg})$, was mechanically shaken with $20 \mathrm{ml}$ of deionized water for 24 hours. The samples were then centrifuged $15,000 \mathrm{rpm} / 15$ minutes and the supernatant stored in in the freezer until analysis. Thawed extracts were diluted 1:1 with $2 \mathrm{~N} \mathrm{H} 2 \mathrm{SO} 4$.

Aliquots $(500 \mu \mathrm{l})$ were measured into heavy walled glass centrifuge tubes and cooled in ice water for 1 hour. Cold KI-I2 reagent $(200 \mu \mathrm{l})$, prepared by dissolving $15.7 \mathrm{~g}$ of iodine and $20.0 \mathrm{~g}$ of $\mathrm{KI}$ in $100 \mathrm{ml}$ water was added and the reactants were gently stirred with a vortex mixture. The tubes were stored $0-4^{\circ} \mathrm{C}$ for 16 hour and then centrifuged at $10.000 \mathrm{rpm}$ for 15 minutes at $0^{\circ} \mathrm{C}$. The supernatant was carefully aspirated with a fine tipped glass tube. Because of the solubility of the complexes in the acid reaction mixture increases markedly with temperature, it is important that the tubes be kept cold until the periodic complex is separated from the acid media. The periodic crystals were dissolved in in $9.0 \mathrm{ml}$ of 1,2dichloroethane. Vigrous vortex mixing was frequently required to effect complete solution in the developing solvent. After 2-2.5 hours, the absorbance was measured at $365 \mathrm{~nm}$ with a UV-Vis Spectrophotometer. Reference standards of Glycine betaine $(100-1000 \mu \mathrm{g} / \mathrm{ml})$ were prepared in $1 \mathrm{~N} \mathrm{H} 2 \mathrm{SO} 4$. Standard curves were prepared with every set of plant samples. Standard were analyzed in duplicates, unknown samples, in triplicate.

\section{Statistical analysis}

For statistical analysis of the data, five biological and three technical replicates from each of the transgenic events were used. Student's $\mathrm{t}$ test was conducted using XLSTAT 2013.5 to analyze all the data to compare the transgenics and control under normal and stress conditions. P value of (P B 0.05) was considered statistically significant.

\section{RT-PCR analysis}

Total RNA was extracted from leaves collected from drought stressed (75 days after stress) transgenic sugarcane plants. Total RNA was isolated using the RNA isolation reagent (BIO-BASIC, Canada).

The isolated total RNA was converted into cDNA using RevertAid ${ }^{\mathrm{TM}} \mathrm{H}$ minus First Strand cDNA Synthesis Kit (MBI Fermentas, USA). The first strand cDNA was used as a template for the amplification of actin (used as internal control), BcZAT12. The following primes used for RT-PCR amplification of actin For: (5' AATGGTCAAGGCTGGTTTTG3') and Rev: (5' CGTACATGGCAGGAACATTG3'), BcZAT12 For: (5' ATCAAGTCGACGG TGGA GAC 3') and Rev: 5' CACCAT CCCC AAACTCAGAT 3'). Temperature profile used for the PCR amplification was as follows: Initial denaturation at $94{ }^{\circ} \mathrm{C}$ for 5 min, followed by 35 cycles of denaturation at $94{ }^{\circ} \mathrm{C}$ for $1 \mathrm{~min}$, annealing at $57^{\circ} \mathrm{C}$ for $1 \mathrm{~min}$, synthesis at $72{ }^{\circ} \mathrm{C}$ for $1 \mathrm{~min}$ and final extension at $72{ }^{\circ} \mathrm{C}$ for $10 \mathrm{~min}$. Presence of amplicon was checked through $1.2 \%$ agarose gel electrophoresis.

\section{Results and Discussion}

Sugarcane genotype, Co86032 is a popular variety occupying large area under cultivation in India. The variety is known high sucrose 
content and is susceptible to drought and salinity. To impart abiotic stress tolerance in Co86032, abiotic stress tolerance gene, BcZAT12gene was transformed into it. Transgenic sugarcane developed showed high level of abiotic stress tolerance in some of the transgenic lines.

Genetic transformation of sugarcane for abiotic stress tolerance

The BcZA12 gene cassette, containing BcZA12 gene flanked by drought inducible promoter, "pLEA", and terminator sequence "Nos", was cloned into the backbone of the binary vector, pCAMBIA1300 was designated as pCAMBIA1300-BcZA12 construct (Figure $1)$.

Hygromycin resistant gene "hpt", which encodes for hygromycin phosphotransferase, was used as plant selectable marker. Agrobacterium tumefaciens strains, LBA4404 (pCAMBIA1300-BcZAT12) were used for transformation of sugarcane cultivar of Co86032 genotypes used for agrobacterium mediated transformation.

Agrobacterium mediated transformation experiments were carried out several times using embryogenic calli of sugarcane cv. Co86032. The LBA4404 in pCAMBIA1300BcZA12 construct was used for Agrobacterium mediated transformation.

After genetic transformation, hygromycin resistant embryogenic calli obtained after third round of selection were transferred to regeneration medium containing $50 \mathrm{mg} / \mathrm{l}$ hygromycin for shoot regeneration. The welldeveloped shoots were separated carefully and transferred to rooting medium for root induction. In total, 45 independent lines of putative transgenic sugarcane lines were generated (Figure 2).
Molecular analysis of putative transgenic plants

PCR analysis of putative transgenic sugarcane plant lines transformed with BcZAT12 gene

In order to confirm the integration of the transgenes, PCR analysis was performed for the presence of BcZAT12 gene and hygromycin (hpt). All the 45 transformed lines showed amplification for BcZAT12gene (Figure 3) and Hygromycin (hpt). All the 45 transgenic lines were found to be positive.

\section{Evaluation of drought and salinity tolerance in transgenic sugarcane plant transformed with BcZAT12 gene}

All the 45 independent transgenic sugarcane plants lines were tested for drought tolerance. After planting transgenic and non-transgenic sugarcane setts in the soil, drought was imposed by not watering for different period of time viz., 15, 30, 45, 60 and 75 days. Both the transgenic and non-transgenic plants did not show morphological variation or wilting upto 30 days. After 60 days without irrigation, control plants showed severely retarded in growth, most leaves rolled out and only few leaves are erect. In case of putative transgenic plants lines, the level of damage was less compared to non-transgenic control plants. However, on subsequent watering, the growth of transgenic lines was almost identical to non-stressed plants, whereas, the control plants were not able to recover and resulted in retarded growth. After 75 days interval, control plants showed complete cessation of growth, most leaves dried and rolling of young leaves with loss of chlorophyll, whereas, the level of damage was less in case of putative transgenic plants lines (Figure 4). Based on the level of damage, the plants were scored as highly tolerant, tolerant, moderately tolerant and susceptible (Table 1). Out of 45 
independent lines of transgenic sugarcane tested, 10 lines of Co86032 were highly tolerant to drought stress.

In addition to drought, the same putative transgenic plants were analyzed for salinity tolerance, by suspending the cut leaf of transgenic and non-transgenic on $100 \mathrm{mM}$ $\mathrm{NaCl}$ solution. After 72 hours, non-transgenic control leaf turned yellow due to loss of chlorophyll, whereas, in case of transgenic plants, leaf of most of the lines remained green or showed less loss of chlorophyll compared to non-transgenic control. After 120 hours, control plant leaf lost the chlorophyll completely and started drying at the cut end. During the same time period, the leaf of the transgenic plant retained most of the green chlorophyll with some region of turning yellow (Figure 5). Ten lines of Co86032 were highly tolerant to salinity stress.

Salinity tolerance further tested in greenhouse condition. Thirty day old seedlings derived from the sugarcane culms (bud chip) of all the 45 putative transgenic plants and nontransgenic plants were used for salt stress treatment by watering the plants with $175 \mathrm{mM}$ $\mathrm{NaCl}$ solution. After 3 days of stress, untransformed control plants started showing yellowing at tip of the leaf. During the same period, the transgenic plant lines remained healthy (Figure 6). After 5 day of salt stress, at least $50 \%$ of the leaves of the untransformed control plants turned yellow and hanged out, whereas, the leaf of transgenic lines started turning yellow at the tip region with few leaves hanging. After 7 day, entire leaves of the control plant dried, whereas, the transgenic plant showed yellowing of the tip and at least half of the leaf hanged out. After 10 days, stressed transgenic plant recovered by watering, whereas, non-transgenic plants did not recovery from stress. In the 45 putative transgenic lines transformed with BcZAT12 gene, 10 lines were highly tolerant to salinity stress.

\section{Expression of BcZAT12 gene in sugarcane}

Leaf samples were collected after 60 days of drought stress in Co86032 transformed with BcZAT12gene and control plant. RT- PCR amplification of BcZAT12 gene was performed to confirm its expression levels in six different transgenic lines. Both the control and transgenic plant lines showed amplification for actin gene (internal control) with same band intensity. However, the amplification of the BcZAT12 gene was noted in all the transgenic plant lines and failed to show amplification in untransformed control plant indicating the expression of BcZAT12 gene in transgenic plants (Figure 7).

\section{Evaluation of drought tolerance in transgenic sugarcane genotype, Co86032 transformed with BcZAT12 gene}

Transgenic sugarcane genotype, Co86032 transformed with abiotic stress tolerant gene, BcZAT12 gene were evaluated for drought stress at morphological, physiological, biochemical and molecular level. Three transgenic lines that showed tolerance to abiotic stress in the first round of screening were used for further evaluation.

\section{Morphological traits}

The morphological traits namely plant height, leaf length, leaf width, internode elongation, number of tillers and numbers of buds produced per plant were measured at 30 days after drought stress (90 DAT) in drought imposed transgenic lines of Co86032 transformed with BcZAT12 gene and untransformed control. During first recovery at 75 DAT, there was no significant plant height difference among the control and the transgenic plant line. However, during reirrigation at 75 days followed by second drought, there was very quick recovery and showed statistically significant increase in 
plant height (which was recorded at 90 DAT) in all the three lines of transgenic sugarcane cv. Co86032 transformed with BcZAT12gene compared to untransformed sugarcane of the same variety.

After 15 days of drought stress (75 DAT), drying of leaf was observed in the basal leaves the drying of the leaves was more pronounced in the control compared to the transgenic lines. The transgenic sugarcane line SS103, SS109 and SS113 showed only marginal basal leaves drying at this stage thereby indicating drought stress (Plate 4). After 30 days of drought stress (90 DAT), there was significant drying of the leaves in the untransformed sugarcane variety Co86032 compared to the all the three transgenic lines transformed with BcZAT12 gene. There was statistically significant reduction in leaf length in untransformed sugarcane variety Co86032 compared to all the three lines of Co86032 transformed with BcZAT12 gene. During drought stress, leaf started drying from the leaf tip thereby reducing the leaf length. When drought stressed plants on re- irrigation, leaf showed recover from stress and rolled leaf expended gradually. In case of transgenic sugarcane variety Co86032 transformed withBcZAT12gene showed slight leaf rolling in some lines. In addition to leaf length, there was marked reduction in the leaf width of the untransformed control plants of variety, Co86032 compared to all the three independent transgenic lines of Co86032 transformed with BcZAT12gene. Length of the first internode (form the base of the sugarcane plant) was measured 30 days (90 DAT) after drought stress. In untransformed control plant of the sugarcane cv. Co86032 showed reduced internode elongation compared to the respective sugarcane variety transformed withBcZAT12. In addition to reduction in the internode elongation, stem thickness was also reduced in the untransformed plants compared to the transgenic lines. When they were plants subjected to drought stress the number of tillers reduced drastically but in case of transgenic plants number of tillers will not reduce under drought stress whereas nontransgenic plants tiller number reduced. The growth of non-transgenic plants under drought stress will be stunted growth whereas transgenic will grow normally. When the plants subjected to severe stress drying of the tiller growth and within 3 to 5th days tiller growth may affected, finally mother plants also will die. Under drought imposed nontransgenic sugarcane plants number of buds reduced dramatically whereas transgenic sugarcane plants number of bud production increased gradually (Table 2). When plants subjected to rewatering healthy buds start to germination whereas nontransgenic plants buds no growth was observed.

\section{Physiological parameters}

With a view to assess drought tolerant condition, physiological parameter such as leaf temperature, relative water content, chlorophyll content, photosynthetic rate, stomatal conductance and transpiration rate were measured between transgenic and nontransgenic sugarcane genotype, Co86032. All the physiological parameters were recorded 30 days (90 DAT) after drought stress (Table 3). Transgenic plants transformed with BcZAT12gene showed statistically reduced leaf temperature compared to untransformed control plants. The reduction in leaf temperature is a measure of drought tolerance as exhibited by the transgenic lines compared to the control plants. Relative water content was higher in all the transgenic lines compared to the control. In addition, the chlorophyll content measured SPAD meter, photosynthetic rate, stomatal conductance and transpiration rate measured using Portable Photosynthesis system showed significant difference compared to control. In particular 
the photosynthetic rate and chlorophyll fluorescence was twofold higher in all the three independent transgenic lines with respect to untransformed control plants. Higher photosynthetic rate in transgenic lines using drought condition is a indicator of increased drought tolerance. Out of the three independent line tested, two lines, SS 16, SS 17 and SS 18 showed statistically significance $(\mathrm{P}<0.01)$ difference with control. This three lines (SS 16, SS 17 and SS 18) displayed greater drought tolerance compared to all other lines. The same lines all showed superior morphological characters in comparison to other four lines. Calculated by three biological replication.

\section{Biochemical parameters}

Biochemical analysis such as proline and glycine betaine was estimation in both the transgenic sugarcane variety Co86032 transformed with BcZAT12 gene and untransformed control (Table 4). The proline content estimated in the drought imposed transgenic sugarcane lines transformed with BcZAT12gene showed 1.0 to 2.3foldincreased accumulation of proline in comparison to untransformed control. The glycine betaine estimated in transgenic sugarcane plants transformed with BcZAT12showed very higher accumulation ranging from 2.21 to 2.94fold increases in independent transgenic lines with respect to control

\section{Expression of BcZAT12 gene under drought stress}

RT-PCR analysis was done in the three independent lines of transgenic sugarcane cv. Co86032 transformed with BcZAT12gene and untransformed control. All the three transgenic lines showed higher expression of the BcZAT12gene transcript (Plate6).

Table.1 Screening for drought and salinity in putative transgenic lines of sugarcane transformed with BcZAT12 stress tolerant genes

\begin{tabular}{|c|c|c|c|c|c|c|c|}
\hline \multirow[t]{2}{*}{ S. No. } & \multirow[t]{2}{*}{ Line number } & \multicolumn{2}{|c|}{ Responses } & \multirow[t]{2}{*}{ S. No. } & \multirow[t]{2}{*}{ Line number } & \multicolumn{2}{|c|}{ Responses } \\
\hline & & Drought & Salinity & & & Drought & Salinity \\
\hline & Co86032 & - & - & 23 & SS 23 & & \\
\hline 1 & SS 01 & +++ & +++ & 24 & SS 24 & +++ & +++ \\
\hline 2 & SS02 & + & + & 25 & SS 25 & +++ & +++ \\
\hline 3 & SS 03 & - & - & 26 & SS 26 & +++ & +++ \\
\hline 4 & SS 04 & ++ & ++ & 27 & SS 27 & - & - \\
\hline 5 & SS 05 & ++ & ++ & 28 & SS 28 & + & + \\
\hline 6 & SS 06 & - & - & 29 & SS 29 & ++ & ++ \\
\hline 7 & SS 07 & ++ & ++ & 30 & SS 30 & ++ & ++ \\
\hline 8 & SS 08 & +++ & +++ & 31 & SS 31 & ++ & ++ \\
\hline 9 & SS 09 & ++ & ++ & 32 & SS 32 & - & - \\
\hline 10 & SS 10 & ++ & ++ & 33 & SS 33 & ++ & ++ \\
\hline 11 & SS 11 & +++ & +++ & 34 & SS 34 & ++ & ++ \\
\hline 12 & SS 12 & + & + & 35 & SS 35 & + & + \\
\hline 13 & SS 13 & - & - & 36 & SS 36 & + & + \\
\hline 14 & SS 14 & + & + & 37 & SS 37 & - & - \\
\hline 15 & SS 15 & + & + & 38 & SS 38 & + & + \\
\hline 16 & SS 16 & +++ & +++ & 39 & SS 39 & + & + \\
\hline 17 & SS 17 & +++ & +++ & 40 & SS 40 & + & + \\
\hline 18 & SS 18 & +++ & +++ & 41 & SS 41 & + & + \\
\hline 19 & SS 19 & ++ & ++ & 42 & SS 42 & + & + \\
\hline 20 & SS 20 & +++ & +++ & 43 & SS 43 & + & + \\
\hline 21 & SS 21 & ++ & ++ & 44 & SS 44 & + & + \\
\hline 22 & SS 22 & ++ & ++ & 45 & SS 45 & + & + \\
\hline
\end{tabular}

+++ - Indicate Highly tolerant, ++ - Tolerant, + - Moderately Tolerant, - - Susceptible. 
Tables.2 Morphological characters of drought impose transgenic sugarcane transformed with drought tolerant genes

\begin{tabular}{|l|l|l|l|l|l|l|}
\hline Samples & $\begin{array}{l}\text { Plant height } \\
\text { (In cm) }\end{array}$ & $\begin{array}{l}\text { Leaf length }(\text { In } \\
\text { cm) }\end{array}$ & $\begin{array}{l}\text { Leaf width } \\
\text { (In cm) }\end{array}$ & $\begin{array}{l}\text { Internode } \\
\text { elongation } \\
\text { (In cm) }\end{array}$ & $\begin{array}{l}\text { Tillers growth } \\
\text { from collar } \\
\text { region } \\
\text { (In nos) }\end{array}$ & $\begin{array}{l}\text { Number of } \\
\text { buds } \\
\text { produced/pla } \\
\text { nt (In nos) }\end{array}$ \\
\hline BcZAT12 & & & & & & \\
\hline Co 86032 & $170.4 \pm 10.69$ & $70.66 \pm 12.56$ & $2.51 \pm 0.30$ & $3.03 \pm 0.56$ & $16.25 \pm 12.12$ & $1.66 \pm 0.33$ \\
\hline SS 16 & $183.87 \pm 5.87$ & $75 \pm 8.63$ & $3.46 \pm 0.12$ & $4 \pm 0.25$ & $38.5 \pm 23.11$ & $2 \pm 0.57$ \\
\hline SS 17 & $186.1 \pm 6.89^{*}$ & $86.2 \pm 7.01^{*}$ & $3.76 \pm 0.24 *$ & $5.13 \pm 1.38^{*}$ & $41.53 \pm 14.36^{*}$ & $2.5 \pm 1.25^{*}$ \\
\hline SS 18 & $202.07 \pm 9.28^{*}$ & $108.66 \pm 9.72^{*}$ & $3.81 \pm 0.05^{*}$ & $4 \pm 1.73$ & $38.6 \pm 18.27^{*}$ & $2 \pm 0.57$ \\
\hline$* * \mathbf{P}<\mathbf{0 . 0 1}$ & $* \mathbf{P}<\mathbf{0 . 0 5}$ & & & & & \\
\hline
\end{tabular}

Calculated by three biological replication

Table.3 Physiological characters of drought impose transgenic sugarcane transformed with drought tolerant gene

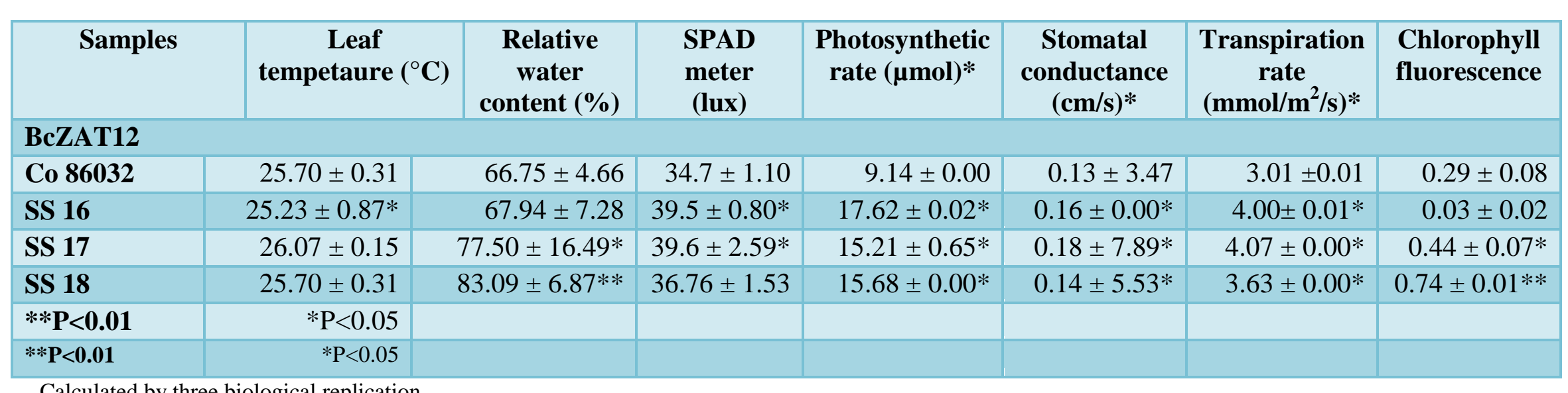

Calculated by three biological replication 
Table.4 Biochemical characters of drought impose transgenic sugarcane transformed with drought tolerant gene

\begin{tabular}{|l|l|l|}
\hline \multicolumn{1}{|c|}{ Samples } & $\begin{array}{c}\text { Average proline } \\
(\boldsymbol{\mu g} / \mathbf{g})\end{array}$ & $\begin{array}{c}\text { Aerage Glycine } \\
\text { betaine }(\boldsymbol{\mu g} / \mathbf{g})\end{array}$ \\
\hline BcZAT12 & \multicolumn{2}{|c|}{} \\
\hline Co 86032 & $51.11 \pm 10.29$ & $19.63 \pm 4.68$ \\
\hline SS 16 & $54.35 \pm 6.04$ & $57.86 \pm 3.47$ \\
\hline SS 17 & $121.09 \pm 8.44 *$ & $43.40 \pm 7.27 *$ \\
\hline SS 18 & $81.79 \pm 0.95$ & $45.25 \pm 0.99$ \\
\hline$* * \mathbf{P}<\mathbf{0 . 0 1}$ & $* \mathrm{P}<0.05$ & \\
\hline
\end{tabular}

Calculated by three biological replication

Figure.1 $B c Z A T 12$ gene construct

The figure shows the BcZAT12gene construct in the T-DNA region pCAMBIA 1300

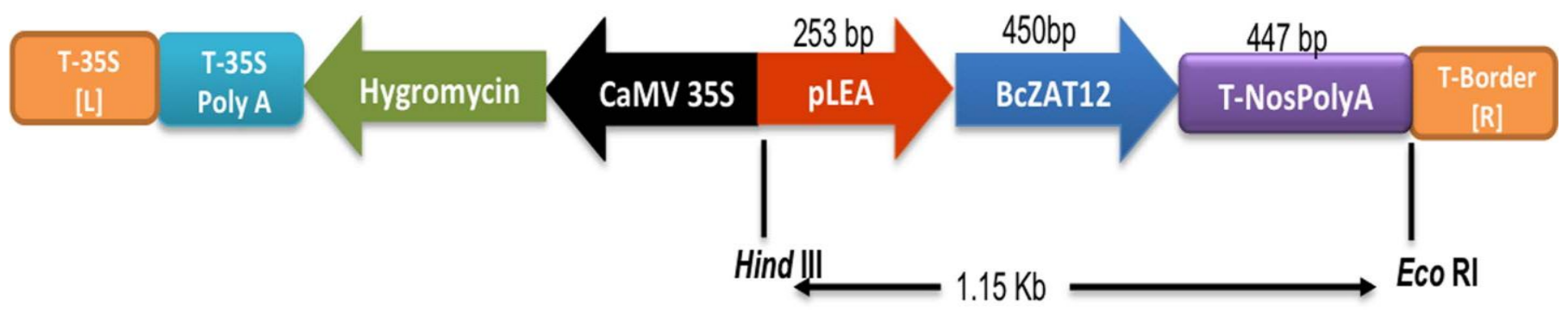

Figure.5 Screening for salt stress in leaf disc of transgenic sugarcane cv. Co86032 at 100mM $\mathrm{NaCl}$

Square leaf disc indicates that untransformed sugarcane plant. Circular leaf disc indicate SS 17 and SS 18 are transgenic lines.

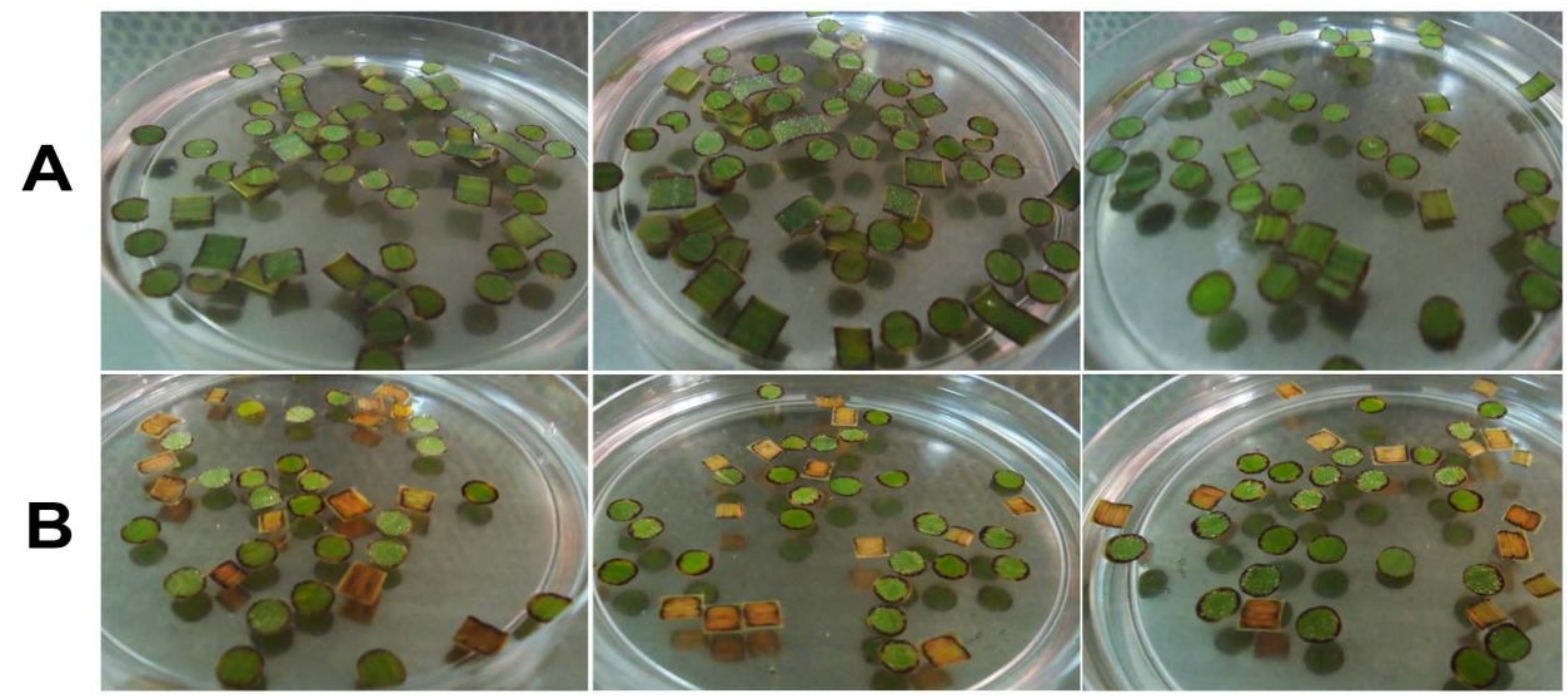


Figure.2 Agrobacterium mediated genetic transformation of sugarcane Co86032 with BcZAT12 The figure shows the different steps involved in the Agrobacterium mediated genetic transformation of sugarcane cultivar Co 86032

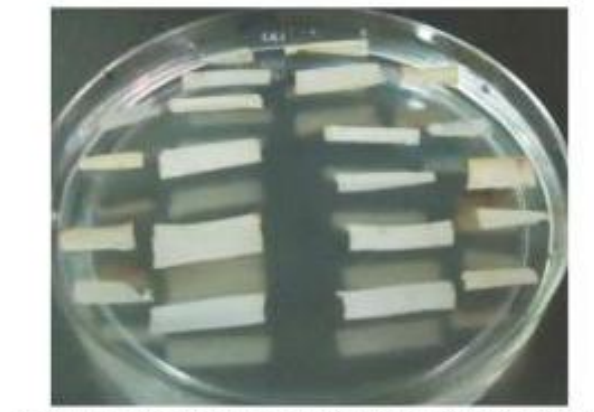

Inoculation of immature leaf roll MS medium with $2,4-D(3 \mathrm{mg} /)$

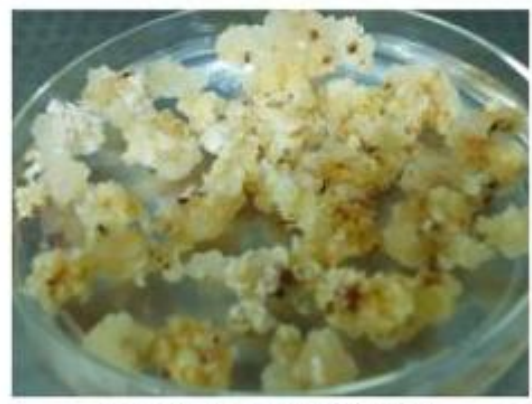

Development of embryogenic calli

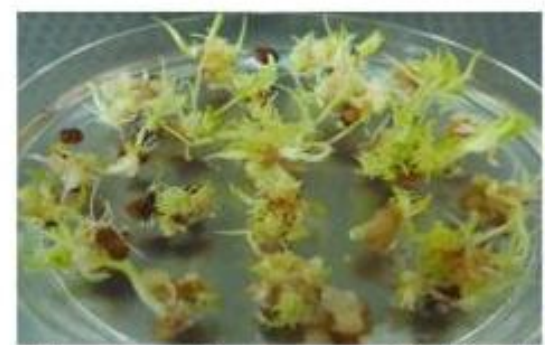

Regeneration of Shoots in presence of hpt (50 $\mathrm{mg} / \mathrm{ll})$

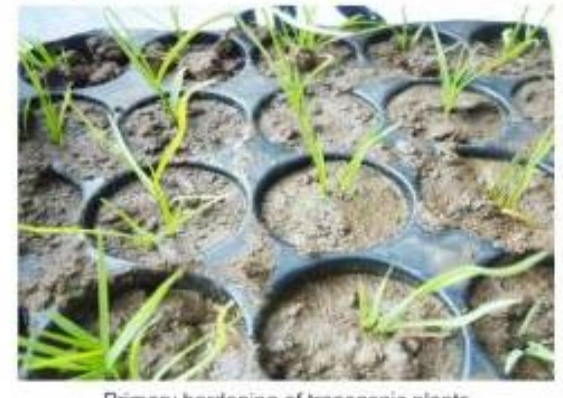

Primary hardening of transgenic plants

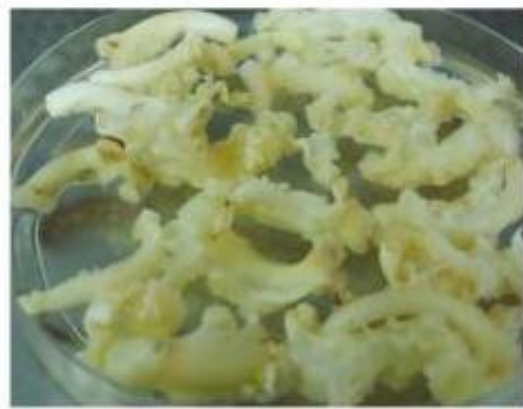

Calli developed from immature leaf roll

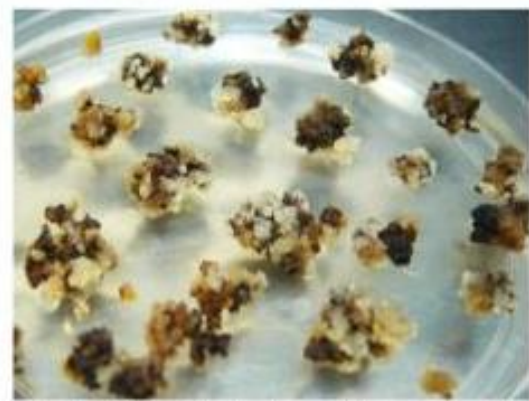

Selected calli after third round selection on MS medium hpt ( $50 \mathrm{mg} /$ )

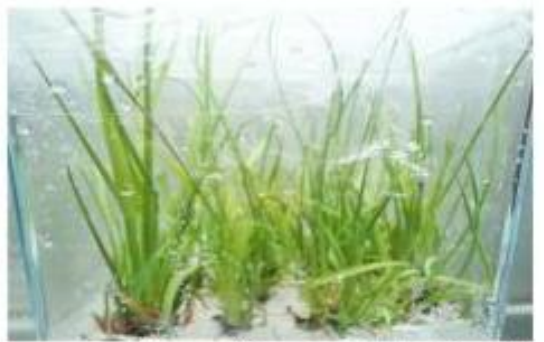

Rooting of shoots in MS medium with hpt (50mg/)

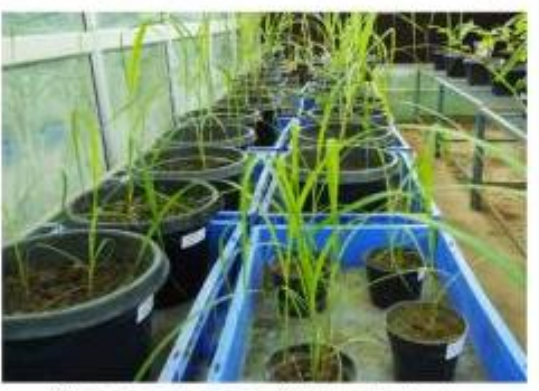

Secondary hardening of transgenic plants 
Figure.3 PCR amplification of BcZAT12 gene in the putative "To" transgenic Sugarcane lines

PCR amplification of $B c Z A T 12$ gene resulted in the amplicon of the expected size $258 \mathrm{bp}$, confirming the transformation event. Ladder denotes 100bp DNA ladder
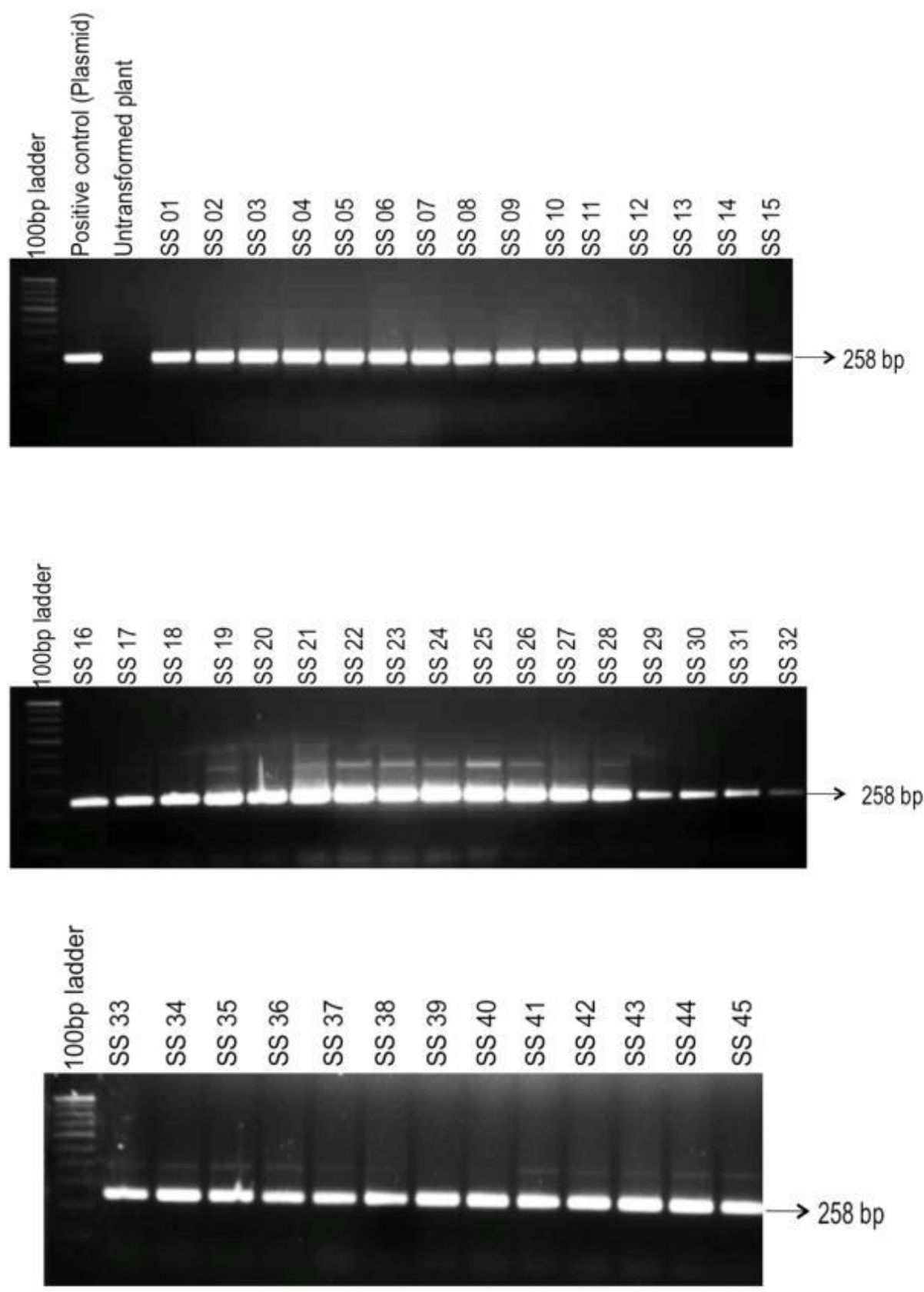
Figure.4 Screening for drought stress in transgenic sugarcane variety Co86032 transformed with BcZAT12 gene

Control indicates that untransformed sugarcane plant. DAT and DAD denote "Day After

Transplanting" and "Day After Drought stress" respectively

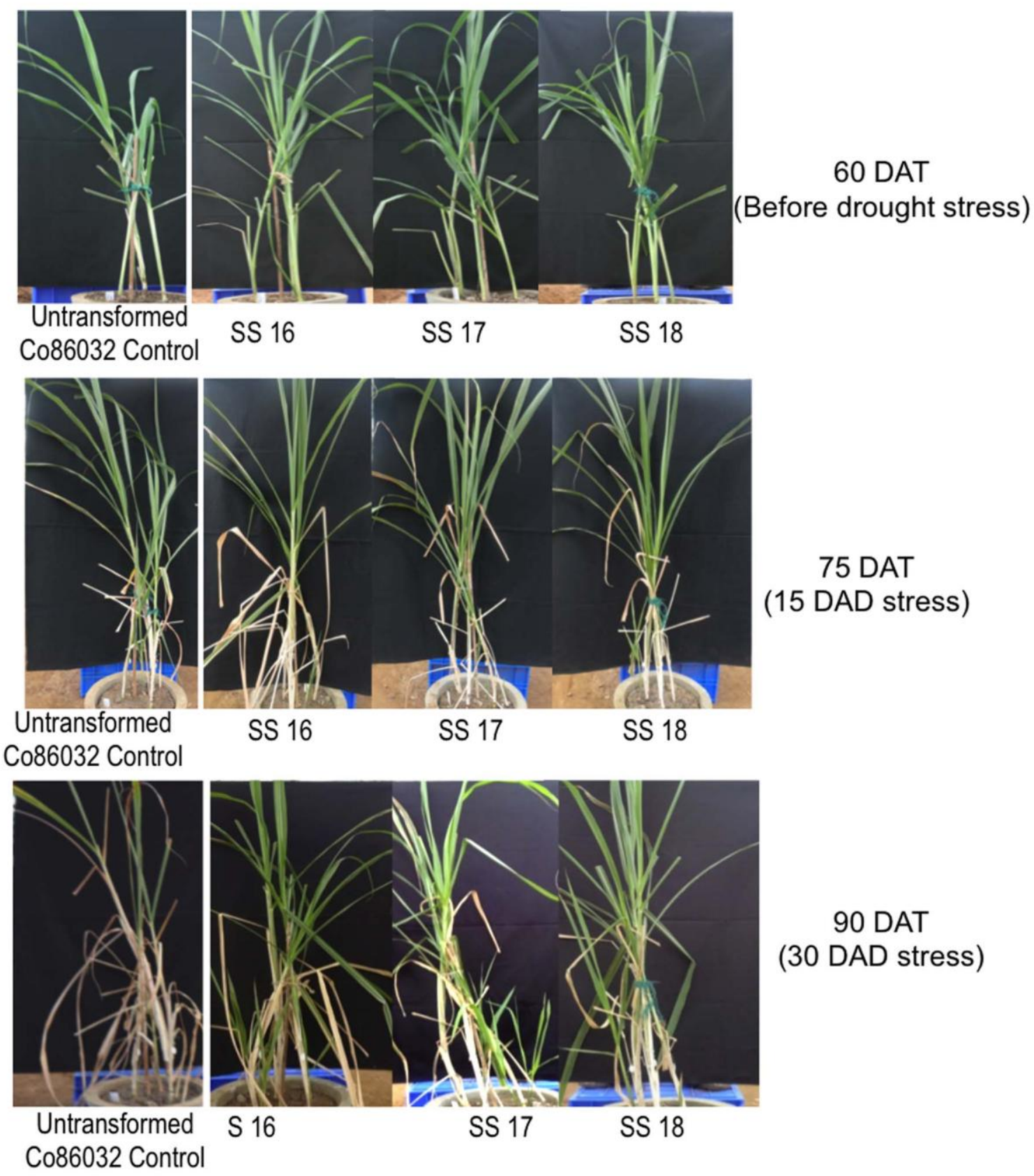


Figure.6.Screening for salt stress in transgenic sugarcane cv. Co86032 at $175 \mathrm{mM} \mathrm{NaCl}$ Control indicates that untransformed sugarcane plant. SS 16, SS 17 and SS 18are transgenic lines.

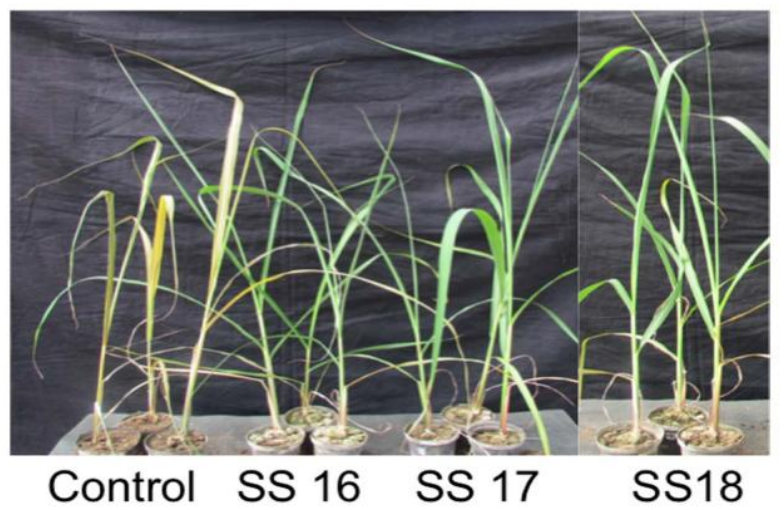

Figure.7 RT-PCR analysis of BcZAT12gene from the leaves of transgenic lines of sugarcane cv. Co86032 transformed with BcZAT12 gene; A) Total RNA isolated from the leaves of droughtstressed transgenic lines of sugarcane. B)Expression of actin gene in the leaves of transgenic

lines of sugarcane. C) Expression of BcZAT12 gene in the leaves of transgenic lines of sugarcane. "Control" indicates that untransformed sugarcane plant. SS indicates transgenic lines; SS 02(susceptible to drought), SS 04(moderately drought tolerant), SS 05(drought tolerant), SS 16, SS 17 and SS 18 (highdrought tolerant)

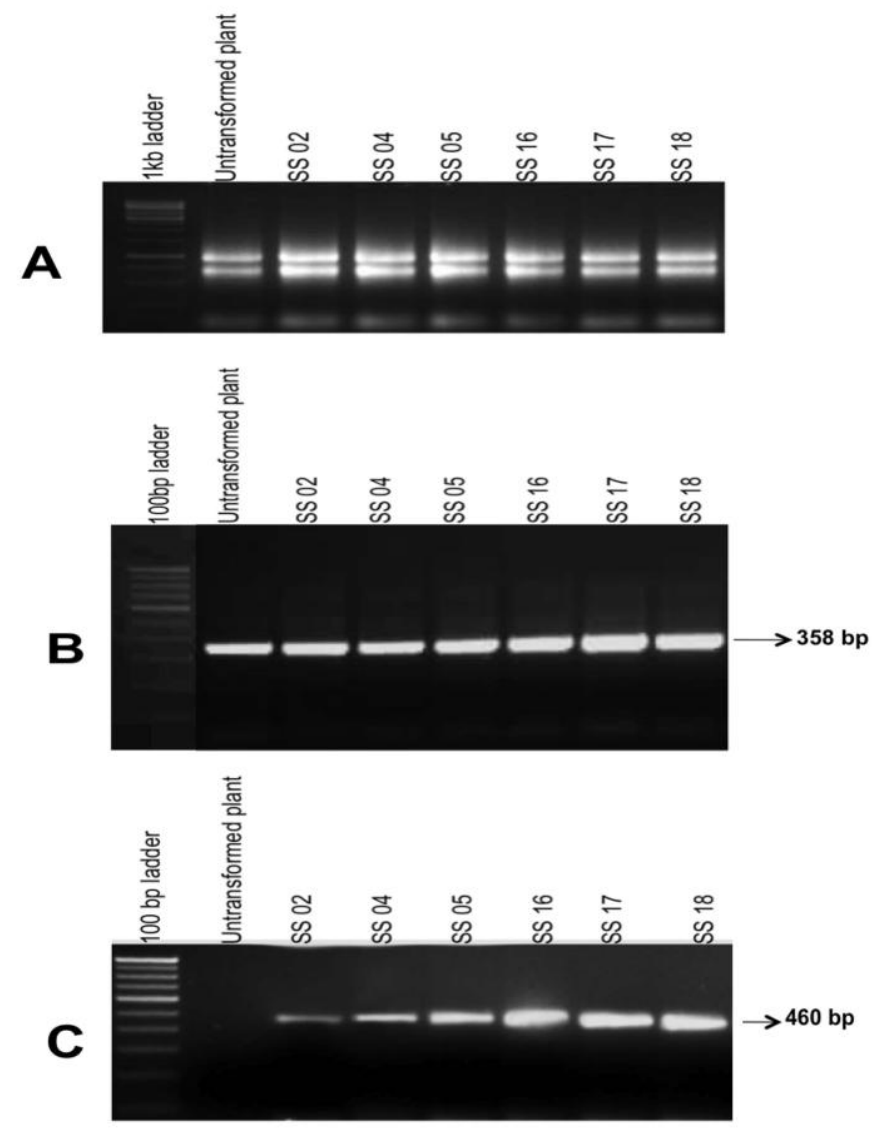


Genetic engineering is a very valuable tool to introduce commercially important traits into elite germplasm of sugarcane. Most of reports on sugarcane transformation have used the agrobacterium mediated transformation method to introduce the transgene indicating that agrobacterium mediated transformation method is the most effective method for sugarcane transformation (Bower and Birch, 1992; Bower et al., 1996; Moore, 1999; Irvine and Mirkov, 1997). The BcZAT12gene was isolated using the yeast one-hybrid screening from Brassica carinata and it is one of the potential genes, which confers drought and salt tolerance. BcZAT12 encodes $\mathrm{C} 2 \mathrm{H} 2$ binding proteins (Liu et al., 1998). pLEA, promoterin Brassica carinata, is a cis-acting element which was induced by drought, high salinity and low temperature stresses (Kasuga et al., 1999). There are several reports indicating the role of BcZAT12 gene in conferring abiotic stress tolerance. Overexpression of the BcZAT12 in transgenic Arabidopsis plants activated the expression of many stress tolerance genes under normal growing conditions and resulted in improved tolerance to drought, salt and freezing (Kasuga et al., 1999).

First attempt to transform wheat with BcZAT12 driven by stress inducible pLEA promoter was done using agrobacterium mediated transformation method (Pellegrineschi et al., 2004). For rice ZAT12 orthologs, OsZAT12were isolated from rice, these OsZAT12 transgenic rice plants had been shown to improve the tolerance to drought, salt, and low temperatures (Dubouzet et al., (2003). Genetic transformation of Arabidopsis, petunia, tomato, peanut, rice and Brassica species with BcZAT12 gene had resulted in enhanced multiple stress tolerance (i.e., drought, salt and freeze tolerance) (Hsieh et al., 2002; Pellegrineschi et al., 2004; Ito et al., 2006; Oh et al., 2005; Bhatnagar-Mathuret al., 2007; Benham et al.,
2006; Sun et al 2010., Singh et al 2005.,Kubo et al 1998.,Davletovaet al 2005).

Therefore, it is concluded in the present study, "BCZAT12" gene, under the control of " $p L E A$ " promoter, was utilized for the genetic transformation of sugarcane cultivar "Co86032". A total of 45 independent putative transgenic sugarcane plant lines were generated through agrobacterium mediated transformation method. Firstly, 45 transgenic sugarcane lines expressing transgene "BCZAT12" were generated. The integration of transgene was confirmed using PCR analysis for "BCZAT12" and Hygromycin (hpt) as plant selectable marker. By drought and salt stress screening of these 45 lines, 10 lines, which were highly tolerant to drought and salt, were identified. Out of 10, 3 lines were randomly selected for morphological, physiological, biochemical and molecular analyses. These analyses revealed that growth and vigor, relative water content, photosynthetic rate, transpiration rate, stomatal conductance, chlorophyll content, proline and glycine betaine content were higher in the stress tolerant transgenic plants compared to control plants. Moreover in RTPCR analysis, highly tolerant lines showed higher expression of "BcZAT12" compared toless tolerant lines. These data hint at the possible routes through which "BCZAT12"can confer high levels of drought and salt tolerance in transgenic sugarcane lines. Therefore, this study further corroborates that "BCZAT12" is a promising candidate for use in the improvement of abiotic stress tolerance in other crops.

\section{Acknowledgements}

Authors would like to thank Dr. K. C. Bansal, Director, National Bureau of Plant Genetic Resource, Indian Agricultural Research Institute, New Delhi, providing BcZAT12 gene constructs to transform as genetic 
material. This research was supported by Coauthor from Centre for plant molecular Biology and Biotechnology, Tamil Nadu Agricultural University, Coimbatore.

\section{References}

Behnam B, Kikuchi A,Celebi-Toprak F, Yamanaka S, Kasuga M, YamaguchiShinozaki K and Watanabe KN 2006 The ArabidopsisDREB1A gene driven by the stress-inducible rd29A promoter increases salt-stress tolerance in proportion to its copy number in tetrasomic tetraploid potato (Solanum tuberosum). Plant Biotech. 23 169-177.

Bhatnagar-Mathur P, Devi MJ, Reddy DS, Lavanya M, Vadez V, Serraj R, Yamaguchi-Shinozaki K and Sharma KK 2007 Stress inducible expression of AtDREBla in transgenic peanut (Arachis hypogaea) increases transpiration efficiency. Plant Cell Rep.26 2071-2082.

Blum A 1998 Plant Breeding for Stress Environments. CRC. Press Inc Boca Raton. Florida, Pp. 223.

Bower R and Birch RG 1992 Transgenic sugarcane plants via microprojectile bombardment.Plant J.2 409-416.

Bower R, Elliott AR, Potier BAM and Birch RG $1996 \quad$ High-efficiency, microprojectile-mediated cotransformation of sugarcane, using visible or selectable markers. Mol. Breed. 2 239-249.

Burner DM and Legendre BL 1994 Cytogenetic and fertility characteristics of elite sugarcane clones. Sugarcane 1 6-10.

Chen WP and Kuo TT1993 A simple and rapid method for the preparation of Gram-negative bacterial genomic DNA. Nucleic Acids Res. 212260.

Davletova S, Schlauch K, Coutu J and Mittler
R 2005 The zinc-finger protein Zat12 plays a central role in reactive oxygen and abiotic stress signaling in Arabidopsis. Plant Physiol.139 847856.

Dubouzet JG, Sakuma Y, Ito Y, Kasuga M, Dubouzet EG and Miura S 2003 OsDREB genes in rice, Oryza sativa L. encode transcription activators that function in drought, high salt and cold responsive gene expression. Plant $J$. 33 751-763.

Grattan SR and Grieve CM 1983 Rapid assay for determination of water soluble quaternary ammonium compounds. Plant and Soil.70 303-307.

Hsieh T H, Lee JT, Yang PT, Chiu LH, Charng YY, Wang YC and Chan MT 2002 Heterology expression of the Arabidopsis C-repeat/dehydration response element binding factorl gene confers elevated tolerance to chilling and oxidative stresses intransgenic tomato. Plant Physiol. 129 10861094.

Irvine JE and Mirkov T E 1997 The development of genetic transformation of sugarcane in Texas.Sugar J. $6025-$ 29.

Ito Y, Katsura K, Maruyama K, Taji T, Kobayashi M and Seki M 2006 Functional analysis of rice DREB1/CBF-type transcription factors involved in cold-responsive gene expression in transgenic rice. Plant Cell Physiol, 47 141-153.

James C 2007 Global status of commercialized biotech / GM crops. ISAAA Brief No. 37 1-115. Ithaca, New York.

Kasuga M, Liu Q, Miura S, YamaguchiShinozaki K and Shinozaki K 1999 Improving plant drought, salt, and freezing tolerance by gene transfer of a single stress inducible transcription factor. Nat. Biotechnol. 17 287-291. 
Kubo Ki, Sakamoto A, Kobayashi A, Rybka $\mathrm{Z}$, Kanno $\mathrm{Y}$, Nakagawa $\mathrm{H}$ and Takatsuji H 1998 Cys2/His2 zincfinger protein family of petunia: evolution and general mechanism of target-sequence recognition. Nucleic Acids Res.26 608-615.

Liu Q, Kasuga M, Sakuma Y, Abe H, Miura $\mathrm{S}$, Yamaguchi-Shinozaki $\mathrm{K}$ and Shinozaki K 1998 Two transcription factors, DREB1 and DREB2, with an $E R E B P / A P 2$ DNA binding domain separate two cellular signal transduction pathways in drought and low temperature-responsive gene expression, respectively, in Arabidopsis. Plant Cell, 10 13911406.

Matin A, Sun SS, Nagai C, Bidney D, Houtchens KA and Dela C 1989 Development of a transformation system for sugarcane. VII Int. Congress Plant Tiss.Cell Cult. Amsterdam 68.

Mirkov B D, Bowley SR, Harjanto E and Leprince O 1997 Water deficit tolerance and field performance of transgenic alfalfa overexpressing superoxide dismutase. Plant Physiol, 111 1177-1181.

Moore PH 1999 Progress and development in sugarcane biotechnology. Proc. Int. Soc. Sugar Cane Technol. 23 241-
258.

Oh SJ, Song SI, Kim YS, Jang HJ, Kim SY and Kim M 2005 Arabidopsis CBF3/DREB1A and ABF3 in transgenic rice increased tolerance to abiotic stress without stunting growth. Plant Physiol. 138341-351.

Pellegrineschi A, Reynolds M, Pacheco M, Brito RM, Almeraya R, YamaguchiShinozaki K and Hoisington D 2004 Stress-induced expression in wheat of the Arabidopsis thalianaDREB1A gene delays water stress symptoms under greenhouse conditions. Genome, 47 493-500.

Singh SK, Chinnusamy V andBansal KC 2005 Cloning and characterisation of abiotic stress inducible $\mathrm{C} 2 \mathrm{H} 2$ zinc finger proteins from oil seed Brassica species. EMBL/GeneBank/DDBJ database, cited for Nucleotide sequences, tissue: leaf, EMBL:ABB552-541.

Sun SJ, Guo SQ, Yang X, Bao YM, Tang HJ, Sun H, Huang J and Zhang HS 2010 Functional analysis of a novel Cys2/His2-type zinc finger protein involved in salt tolerance in rice. $J$. Exp. Bot. $612807-2818$.

ToriyamaK and Hinata K 1985 Cell suspension and protoplast culture in rice.Plant Sci.41 179-183

\section{How to cite this article:}

Saravanan, S., K.K. Kumar, M. Raveendran, D. Sudhakar, L. Arul, E. Kokiladevi, T. Raguchander, S. Mani and Balasubramanian, P. 2018. Genetic Engineering of Sugarcane for Drought and Salt Tolerant Transgenic Plants Expressing the BcZAT12 Gene. Int.J.Curr.Microbiol.App.Sci. 7(07): 1594-1613. doi: https://doi.org/10.20546/ijcmas.2018.707.188 